\title{
HUBUNGAN PENGENDALIAN GLUKOSA DARAH DAN MORNING BLOOD PRESSURE SURGE DENGAN KEJADIAN PENYAKIT JANTUNG KORONER PADA PASIEN DIABETES MELITUS TIPE 2 DI RUMAH SAKIT UMUM CUT MEUTIA
}

\author{
Maulina Debbyousha ${ }^{1}$, Harvina Sawitri ${ }^{2}$, Anna Millizia ${ }^{3}$, Erwin Siregar ${ }^{4}$, M.Jailani ${ }^{4}$ \\ ${ }^{1}$ Bagian Ilmu Penyakit Dalam Fakultas Kedokteran Universitas Malikussaleh \\ ${ }^{2}$ Bagian Ilmu Kesehatan Masyarakat Fakultas Kedokteran Universitas Malikussaleh \\ ${ }^{3}$ Bagian Anestesi Fakultas Kedokteran Universitas Malikussaleh \\ ${ }^{4}$ Mahasiswa Program Studi Pendidikan Fakultas Kedokteran Profesi Dokter Universitas Malikussaleh \\ Corresponding Author : harvina.sawitri@unimal.ac.id
}

\begin{abstract}
Abstrak
Pasien diabetes melitus (DM) cenderung menujukkan percepatan proses aterosklerotik dan akibatnya risiko penyakit kardiovaskular lebih tinggi seperti penyakit jantung koroner. DM sering dipersulit dangan komorbiditas lainnya yang berkontribusi terhadap peningkatan risiko penyakit kardiovaskular (seperti, hipertensi, penyakit ginjal kronis, dan dislipidemia). Kontrol glikemik yang tidak adekuat atau terjadinya resistensi insulin mengaktifkan saraf simpatis, yang memicu MBPS berlebihan pada pasien DM. MBPS berlebihan terlibat dalam patogenesis kejadian kardiovaskular pada pagi hari dengan mencetuskan stres hemodinamik. Tujuan umum dari penelitian ini adalah untuk mengetahui hubungan antara pengendalian glukosa darah dan MBPS, serta hubungan antara MBPS dan kejadian penyakit jantung koroner pada pasien diabetes melitus di Rumah Sakit Umum Cut Meutia. Penelitian ini merupakan penelitian observasional analitik dengan rancangan potong lintang (cross sectional). Sumber data dalam penelitian ini diperoleh dari data primer berdasarkan hasil identifikasi karakteristik pasien, pengukuran morning blood pressure surge, kadar gula darah puasa dan pemeriksaan EKG. Hasil penelitian menunjukkan sebesar $75 \%$ responden pada penelitian ini $(\mathrm{n}=32)$ memiliki kadar gula darah puasa yang tidak terkontrol, 53,1\% responden dengan morning hypertension dan 62,5\% responden mengalami Penyakit Jantung Koroner (PJK). Pada analisis bivariat, hasil menunjukkan terdapat hubungan antara kontrol gula darah puasa dengan morning hypertension $(\mathrm{p}$ value $=0.024 \%$ ). Secara umum terdapat hubungan timbal balik antara DM dengan hipertensi.
\end{abstract}

Kata Kunci : diabetes-mellitus, morning-blood-pressure-surge, penyakit-jantung-koroner 


\title{
Relationship of Blood Glucose Control and Morning Blood Pressure Surge With the Event of Coronary Heart Disease in Type 2 Diabetes Melitus Patients in Cut Meutia General Hospital
}

\begin{abstract}
Patients with diabetes mellitus (DM) tend to show acceleration of the atherosclerotic process and consequently higher risk of cardiovascular disease such as coronary heart disease. DM is often complicated by other comorbidities which contribute to an increased risk of cardiovascular disease (such as hypertension, chronic kidney disease and dyslipidemia). Inadequate glycemic control or the occurrence of insulin resistance activates the sympathetic nerve, which triggers excessive MBPS in DM patients. Excessive MBPS is involved in the pathogenesis of cardiovascular events in the morning by triggering hemodynamic stress. The general objective of this study was to determine the relationship between blood glucose control and MBPS, as well as the relationship between MBPS and the incidence of coronary heart disease in patients with diabetes mellitus at Cut Meutia General Hospital. This study was an observational analytic study withcross sectionaldesign. Sources of data in this study were obtained from primary data based on the results of identification of patient characteristics, measurement of surge morning blood pressure, fasting blood sugar levels and EKG examination. The results showed that $75 \%$ of respondents in this study $(n=32)$ had uncontrolled fasting blood sugar levels, $53.1 \%$ of respondents with morning hypertension and $62.5 \%$ of respondents experienced Coronary Heart Disease (CHD). In bivariate analysis, the results showed that there was a relationship between fasting blood sugar control and morning hypertension ( $\mathrm{p}$ value $=0.024 \%$ ). In general there is a reciprocal relationship between DM and hypertension.
\end{abstract}

Keywords: diabetes-mellitus, morning-blood-pressure-surge, coronary-heart-disease 


\section{PENDAHULUAN}

Pagi hari merupakan periode dengan insidensi tertinggi kejadian kardiovaskular termasuk infark miokardiak, kematian mendadak, dan stroke. Hal tersebut ditandai oleh perubahan neurohormonal, khususnya, aktivasi sistem saraf simpatis menyebabkan peningakatan tekanan darah yang cepat yang disebut sebagaimorning blood pressure surge (MBPS). ${ }^{1}$ Tekanan darah turun pada malam hari disebabkan oleh penurunan aktivitas simpatik, dan kemudian meningkat tajam pada pagi hari ketika penderita terbangun. ${ }^{2}$

Banyak penelitian dalam beberapa dekade terakhir telah menujukkan variasi diurnal dalam onset kelainan kardiovaskular akut pada pasien hipertensi, seperti sindrom koroner akut, stroke iskemik dan stroke hemoragik yang terjadi pada pagi hari (06:00 pagi sampai sore hari). ${ }^{3}$ Bukti kuat pertama mengenai hubungan MBPS dengan kejadian kardiovaskular tersedia pada tahun 2003 ketika Kario et al melaporkan hubungan independen antara MBPS dan infark serebral 'silent' dan insidensi stroke. ${ }^{4}$ Beberapa tahun kemudian, sebuah laporan oleh penelitian Ohasama diterbitkan yang mengindikasikan hubungan MBPS dengan stroke hemoragik saja. ${ }^{5}$

Penelitian prospektif menujukkan MBPS yang lebih tinggi pada pagi hari menjadi faktor risiko independen terjadinya aterosklerotik melebihi pemantauan tekanan darah ambulatori dan tekanan darah pada malam hari. ${ }^{4}$ Mekanisme molekuler yang berkaitan dengan puncak MBPS dan plak aterosklerotik yang lemah masih belum jelas, walaupun inflamasi, yang memainkan peran sentral pada kaskade yang menghasilkan erosi dan retaknya plak juga berkaitan dengan MBPS. $^{6}$

\section{METODE PENELITIAN}

Penelitian ini merupakan penelitian observasional analitik dengan rancangan potong lintang (cross sectional), dilakukan di BLUD RSU Cut meutia Kabupaten Aceh Utara. Populasi dalam penelitian ini adalah pasien rawat inap yang menderita DM tipe 2 pada BLUD RSU Cut Meutia Kabupaten Aceh Utara sejak tanggal 1 januari 2019 s.d. 31 januari 2019. Sampel adalahseluruh pasien rawat inap yang menderita DM tipe 2 pada BLUD RSU Cut Meutia Kabupaten Aceh Utara dan memenuhi kriteria eksklusi dan inklusi.

Kriteria inklusi:

1. Menderita DM Tipe 2

2. Pasien yangbersedia menjadi subyek penelitian Jurnal Averrous Vol.5 No.1 Mei 2019 
Kriteria eksklusi

1. Pasien yang menderita stroke dan atau transcient ishemic attack.

2. Pasien yang memiliki bukti klinis penyakit arteri perifer.

3. Pasien dengan retinopati diabetikum.

4. Pasien dengan penyakit ginjal kronis.

Sumber data dalam penelitian ini diperoleh dari data primer berdasarkan hasil identifikasi karakteristik pasien, pengukuran morning blood pressure surge, kadar gula darah puasa dan pemeriksaan EKG.

\section{HASIL PENELITIAN}

Jumlah sampel pada penelitian ini sebesar 32 orang. Pada penelitian ini didapatkan kadar gula darah puasa yang tidak terkontrol sebesar 75\% dan kadar gula darah puasa yang terkontrol sebesar $25 \%$.

\section{FASTING BLOOD GLUCOSE}

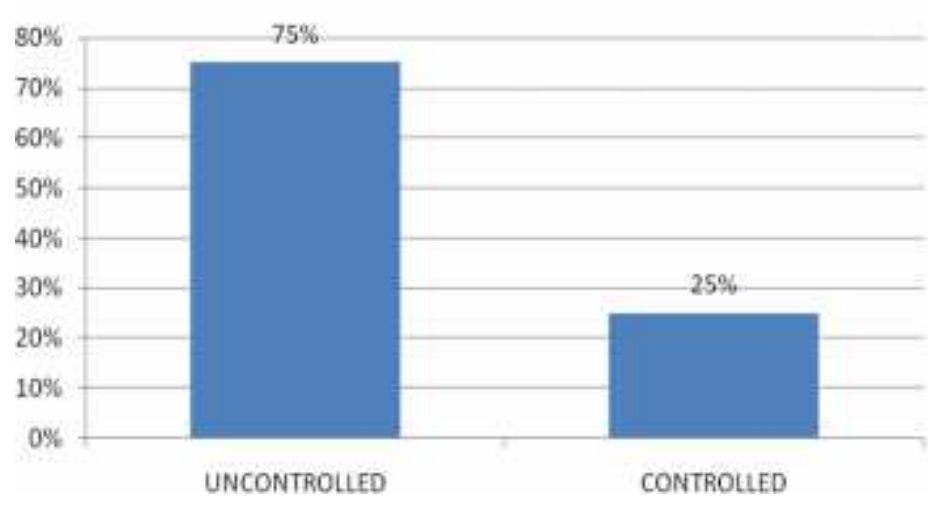

Gambar 1. Grafik kontrol gula darah

Pada penelitian ini terdapat 53,1\% responden dengan morning hypertension dan 46,8\% sisanya normal.

\section{MORNING HYPERTENSION}

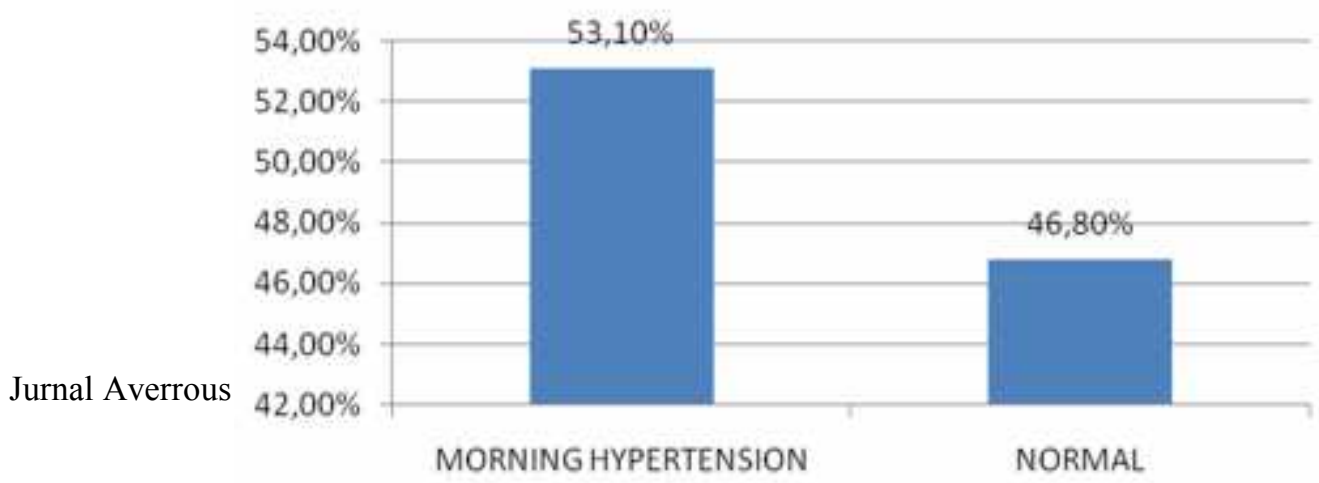




\section{CORONARY HEART DISEASE EVENT}

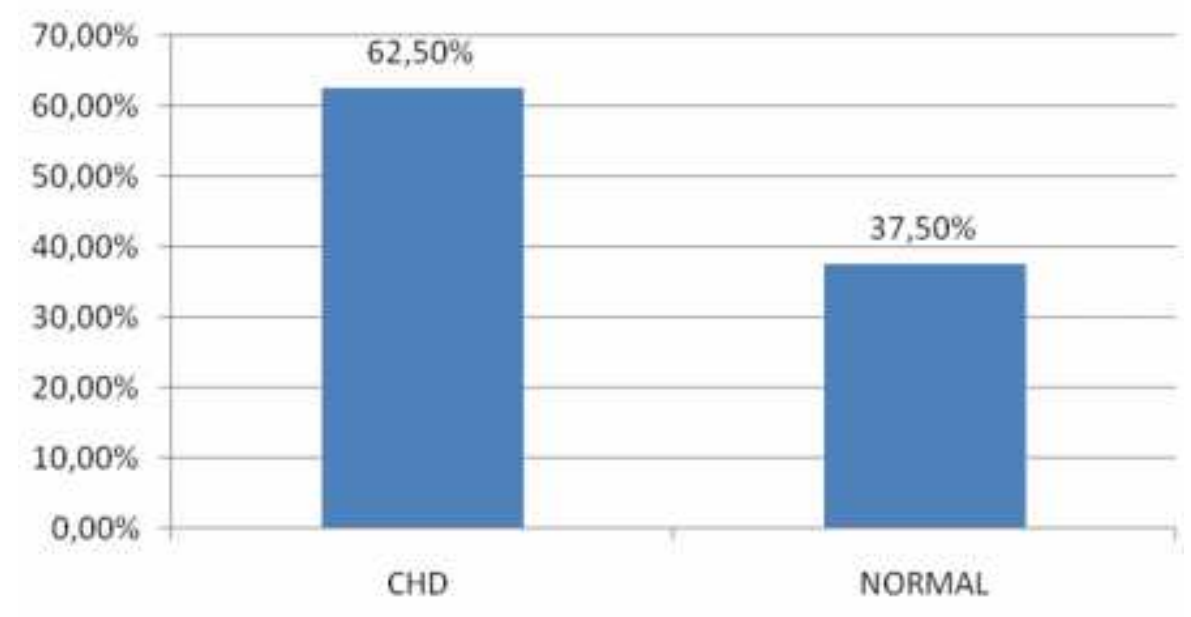

Gambar 3. Grafik kejadian PJK

Sebagian besar responden $(62,5 \%)$ pada penelitian ini mengalami PJK, sementara sisanya $(37,5 \%)$ normal.

Pada penelitian ini didapatkan $43,75 \%$ responden dengan PJK dan morning hypertension, 9,37\% responden dengan morning hypertension tanpa PJK, 18,75 \% responden dengan PJK tanpa morning hypertension, dan 28,12 \% tanpa keduanya. Peneltian ini juga menunjukkan terdapat hubungan antara morning hypertension dengan penyakit jantung koroner $(\mathrm{p}$ value $=0.035)$.

\section{MORNING HYPERTENSION AND CORONARY HEART DISEASE}

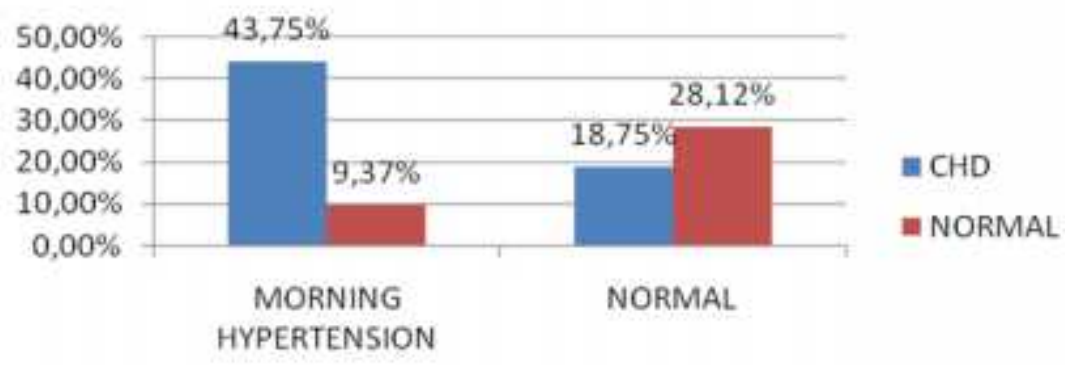

Tabel 1. Hubungan Pengendalian Gula Darah dengan Penyakit Jantung Koroner

\begin{tabular}{|c|c|c|c|c|}
\hline \multirow{2}{*}{$\begin{array}{c}\text { Kendali Gula } \\
\text { Darah }\end{array}$} & \multicolumn{2}{|c|}{ Penyakit Jantung Koroner } & Total & P value \\
\cline { 2 - 3 } & Ya & Tidak & & \\
\hline Tidak terkendali & $16(66,7 \%)$ & $8(33,3 \%)$ & $24(100 \%)$ & \\
\hline
\end{tabular}




\begin{tabular}{|c|c|c|c|c|}
\hline Terkendali & $4(50 \%)$ & $4(50 \%)$ & $8(100 \%)$ & \multirow[t]{2}{*}{0,024} \\
\hline Total & & & $32(100 \%)$ & \\
\hline
\end{tabular}

Terdapat $50 \%$ responden pada penelitiam ini dengan morning hypertension dan guladarah puasa tidak terkontrol, 25\% dengan gula darah puasa tanpa morning hypertension, $3,12 \%$ responden dengan morning hypertension dan gula darah puasa terkontrol, serta 21,87 $\%$ responden dengan gula darah puasa terkontrol dan tanpa morning hypertension. Pada analisis bivariate menggunakan Chi square, penelitian ini menunjukkan terdapat hubungan antara control gula darah puasa dengan morning hypertension ( $\mathrm{p}$ value $=0.024 \%$ ).

\section{PEMBAHASAN}

Sebesar $75 \%$ responden pada penelitian ini $(\mathrm{n}=32)$ memiliki kadar gula darah puasa yang tidak terkontrol. Hal ini sesuai dengan penelitian Ramadhan dan Hanum(2016) di Banda Aceh dimana lebih dari 60\% responden memiliki kadar gula darah puasa yang tidak terkontrol. Pada peneitian tersebut juga didapatkan hubungan yang signifikan antara kadar gula darah puasa dan kadar gula darah 2 jam PP dengan kadar HbA1c dengan nilai $p<0,001$ $(\mathrm{n}=85)$. $^{11}$

HbA1c, Gula darah puasa dan 2 jam post prandial(PP) merupakan indikator kontrol glikemik. Pengontrolan DM dilihat dari dua hal yaitu glukosa darah sesaat dan glukosa darah jangka panjang. Pemantauan glukosa darah sesaat dilihat dari glukosa darah puasa dan 2 jam PP, sedangkan pengontrolan glukosa darah jangka panjang dengan pemeriksaan HbA1c.Pengontrolan glikemik pada penderita DM penting dilakukan untuk mencegah berbagai komplikasi. ${ }^{12}$ Glukosa darah puasa yang tinggi beresiko 12,94 kali terjadi retinopati diabetik. ${ }^{13}$

Pada penelitian ini terdapat 53,1\% responden dengan morning hypertension. Penyebab utama peningkatan Tekanan darah (TD) di pagi hari mungkin adalah aktivasi sistem saraf simpatik. ${ }^{13}$ Tekanan darah pagi lebih tinggi selama hari kerja, terutama Senin, daripada selama akhir pekan, dan selama musim semi dan musim dingin daripada selama musim panas dan musim gugur, kemungkinanhal ini dikarenakan oleh stres tinggi yang disebabkan oleh pekerjaan atau cuaca dingin. ${ }^{14,15}$ Garam makanan juga dapat menjadi faktor penting untuk memperburuk lonjakan TD pagi. Dalam sebuah studi eksperimental klinis, asupan makanan tinggi garam meningkatkan TD pagi hari pada pasien dengan hipertensi yang tidak sensitif terhadap garam. ${ }^{16}$

Jurnal Averrous Vol.5 No.1 Mei 2019 
Pada pasien hipertensi yang mendaapat pengobatan, penggunaan obat antihipertensi yang tidak adekuat dapat menjadi penyebab morning hypertension yang tidak terkontrol. Dalam sebuah penelitian yang melibatkan pasien rawat jalan di rumah sakit tersier di Beijing, prevalensi morning hypertension yang tidak terkontrol bervariasi secara substansial di seluruh penggunaan beberapa calcium channel blockers: 46,3\% $(\mathrm{n}=136)$ dengan amlodipine, 70,5\% $(\mathrm{n}=78)$ dengan gastrointestinal nifedipine sistem terapi, dan 73,8\% $(\mathrm{n}=34)$ dengan slow-release felodipine. ${ }^{17}$

Pada penderita DM resistensi insulin diketahui menstimulasi aktivitas simpatis dengan memengaruhi metabolisme adipositokin, seperti leptin, ${ }^{9}$ selain itu insukin juga dapat merangsang reabsorpsi natrium pada tubulus ginjal. ${ }^{18}$ Kedua hal tersebut mungkin dapat berkontribusi pada peningkatan tekanan darah penderita DM di pagi hari.

Penelitian ini menunjukkan 62,5\% responden mengalami Penyakit Jantung Koroner (PJK). Penyakit jantung koroner adalah penyebab mortalitas dan morbiditas yang paling umum pada populasi diabetes. ${ }^{19}$ Angka kematian akibat PJK di Amerika Serikat 1,7 kali lebih tinggi di antara orang dewasa ( $>18$ tahun) dengan DM daripada mereka yang tidak didiagnosis DM, sebagian besar karena peningkatan risiko stroke dan infark miokard. ${ }^{20}$ Peningkatan risiko kematian akibat PJK pada pasien diabetes ditemukan pada pria dan wanita. Risiko relatif untuk morbiditas dan mortalitas PJK pada orang dewasa dengan diabetes berkisar dari 1 hingga 3 pada pria dan 2 sampai 5 pada wanita dibandingkan dengan mereka yang tanpa DM. ${ }^{21}$

Diabetes memliki hubungan dengan kejadian PJK, dimana berkaitan dengan pengelompokan faktor risiko seperti dislipidemia, hipertensi, obesitas, dan hiperglikemia di hadapan resistensi insulin. Selain itu, diabetes dikaitkan dengan inflamasi dan pro-trombotik, memperburuk perkembangan atherothrombosis. Resistensi insulin dan hiperglikemia berkontribusi pada terjadinya disfungsi sel endotel dan peningkatan stres oksidatif, yang berpuncak pada percepatan aterosklerosis.Diabetes melitus dan resistensi insulin dikaitkan dengan ekspresi berlebih sitokin oleh jaringan adiposa termasuk tumor necrosis factor- $\alpha$, interleukin (IL) -1, IL-6, leptin, resistin MCP-1, PAI-1, fibrinogen dan angiotensin.Pembentukan dan fungsi bekuan darah juga secara langsung dipengaruhi oleh resistensi insulin dan hiperglikemia, dengan meningkatnya kadar faktor koagulasi dan protein anti-fibrinolitik dan jaringan fibrin yang lebih tahan terhadap lisis, ditambah dengan peningkatan aktivasi trombosit. ${ }^{22}$ Banyak penelitian telah menemukan bahwa penderita diabetes telah meningkatkan ekspresi reseptor glikoprotein IIB / IIIA dan vWF, yang Jurnal Averrous Vol.5 No.1 Mei 2019 
bertanggung jawab untuk aktivasi platelet. $^{23,24}$ Pasien dengan DM juga mengalami peningkatan inhibitor aktivator plasminogen tipe 1 yang dapat menurunkan fibrinolisis, meningkatkan pembentukan trombus dan mempercepat pembentukan plak. ${ }^{25}$

Pada analisis bivariate, penelitian ini menunjukkan terdapat hubungan antara control gula darah puasa dengan morning hypertension $(\mathrm{p}$ value $=0.024 \%$ ). Secara umum terdapat hubungan timbal balik antara DM dengan hipertensi. Di satu sisi pasien dengan DM memiliki risiko mengalami hipertensi lebih tinggi dibandingkan mereka yang tidak menderita DM. ${ }^{26}$ Di sisi laini kedua penyakit ini dapat terjadi bersamaan, dan kemudian interaksi dari kedua penyakit ini dapat menyebabkan masalah kesehatan lain, seperti meningkatkan risiko perkembangan stroke. ${ }^{27}$

Penelitian yang dilakukan oleh Yaogai et al. (2018) menunjukkan terdapat hubungan TD dengan GDP, dan dan hubungan ini berbeda menurut jenis kelamin. GDP dikaitkan dengan TD di hampir semua kuantil pada pria, namun pada wanita, GDP memiliki asosiasi positif dengan hanya TD sistol dalam kuantil tinggi. ${ }^{28}$

Peneltian ini juga menunjukkan terdapat hubungan antara morning hypertension dengan penyakit jantung koroner $(\mathrm{p}$ value $=0.035)$. Studi sebelumnya menunjukkan stroke iskemik dan kejadian koroner sering terjadi pada dini hari. ${ }^{29,30}$ Tekanan darah (TD) juga biasanya memuncak di pagi hari.Peningkatan tekanan darah pagi hari dapat menjadi ukuran yang relevan secara klinis untuk memprediksi risiko PJK. ${ }^{31}$

Terdapat bukti bahwa pasien denganmorning hypertension yang tidak diobati memberikan risiko kardiovaskular yang lebih tinggi tinggi dibandingkandengan pasien dengan hipertensi yang diobati. ${ }^{32}$ Dalam studi J-HOP (Japan Morning Surge Home Blood Pressure), pasien dengan TD pagi yang tidak terkontrol memiliki risiko lebih tinggi terkena stroke. ${ }^{33}$ Dalam studi HONEST (Home Blood Pressure Measurement With Olmesartan Naive Patients to Establish Standard Target Blood Pressure) menunjukkan bahwa pasien dengan TD sistolik klinik yang terkontrol dengan baik $(<130 \mathrm{~mm} \mathrm{Hg})$, pasien dengan TD sistolik pagi hari $\geq 145 \mathrm{~mm} \mathrm{Hg}$ memiliki risiko kardiovaskular yang lebih tinggi (rasio hazard, 2,47) dibandingkan dengan TD sistolik pagi $<125 \mathrm{~mm} \mathrm{~mm} \mathrm{Hg.}{ }^{34}$ Pasien hipertensi dengan peningkatan tekanan darah pagimeningkatkan kadar makrofag, sel $\mathrm{T}$, dan tumor necrosis factor- $\alpha$ pada atherosclerotic plaque yang terdapat arteri karotid dibandingkan dengan mereka yang tanpa Morning Blood Pressure Surge(MBPS) berlebihan, menunjukkan adanya hubungan antara MBPS dan cedera vaskular pada pasien hipertensi. ${ }^{35}$ 
MBPS tampaknya memainkan peran paling penting dalam pengembangan disfungsi endotel, sebagaimana tercermin oleh asosiasi terkuat dari MBPS dengan risiko CVD. ${ }^{36}$ Karena MBPS dapat meningkatkan peregangan mekanis pada sel endotel, hal ini meningkatkan produksi superoksida yang diturunkan dari endotelium, sehingga menyebabkan inaktivasi NO. ${ }^{10,37}$

Eto et al. (2003) melaporkan bahwa fluktuasi TD pada tikus secara signifikan mengganggu fungsi endotelial dengan mengurangi pelepasan NO yang diinduksi asetilkolin dari cincin aorta. ${ }^{38,39}$ MBPS juga memiliki hubungan dengan terganggunya FMD(flowmediated dilation) yang merupakan marker dari kerusakan endotel. ${ }^{38}$

\section{KESIMPULAN}

Pasien diabetes melitus (DM) cenderung menujukkan percepatan proses aterosklerotik dan akibatnya risiko penyakit kardiovaskular lebih tinggi seperti penyakit jantung koroner. DM sering dipersulit dangan komorbiditas lainnya yang berkontribusi terhadap peningkatan risiko penyakit kardiovaskular (seperti, hipertensi, penyakit ginjal kronis, dan dislipidemia). Diabetes memliki hubungan dengan kejadian PJK, dimana berkaitan dengan pengelompokan faktor risiko seperti dislipidemia, hipertensi, obesitas, dan hiperglikemia di hadapan resistensi insulin. Stroke iskemik dan kejadian koroner sering terjadi pada dini hari. Tekanan darah juga biasanya memuncak di pagi hari.Peningkatan tekanan darah pagi hari dapat menjadi ukuran yang relevan secara klinis untuk memprediksi risiko PJK.Pada penelitian ini didapatkan hubungan antara kontrol gula darah dengan morning hypertension serta terdapat hubungan antara morning hypertension dengan kejadian PJK.

\section{REFERENSI}

1. Billo G, Grillo A, Guida V, Parati G. Morning blood pressure surge: pathophysiology, clinical relevance and therapeautic aspects. Dove Medical Press 2018;11:47-56.

2. Mancia G, Ferrari A, Gregorini L, Parati G, Pomidossi G, Bertinieri G, et al. Blood pressure and heart rate variabilities in normotensive and hypertensive human beings. Circ Res 1983;53:96-104.

3. Nuthalapati RK, Indukuri BR. Association between glycemic control and morning blood surge with vascular endothelial dysfunction in type 2 diabetes mellitus patients. Indian J Endocr Metab 2016;20:182-8.

4. Kario K, Pickering TG, Umeda Y, et al. Morning surge in blood pressure as a predictor of silent and clinical cerebrovascular disease in elderly hypertensives: a prospective study. Circulation. 2003;107: 1401-1406.

5. Metoki H, Ohkubo T, Kikuya M, et al. Prognostic significance for stroke of a morning pressor surge and a nocturnal blood pressure decline: the Ohasama study. Hypertension. 2006;47:149-154 
6. Marfella R, Siniscalchi M, Nappo F, Gualdiero P, Esposito K, Sasso FC, et al. Regression of carotid atherosclerosis by control of morning blood pressure peak in newly diagnosed hypertensive patients. Am J Hypertens 2005;18:308-18..

7. Kannel WB, Schwartz MJ, McNamara PM. Blood pressure and risk of coronary heart disease: The Framingham Study 1969. Chest 2009;136 5 Suppl: e23.

8. Del Rio G, Carani C, Baldini A, Marrama P, Della Casa L. Chronobiology of catecholamine excretion in normal and diabetic men. $\mathrm{J}$ Endocrinol Invest 1990;13:575-80.

9. Smith MM, Minson CT. Obesity and adipokines: Effects on sympathetic overactivity. J Physiol 2012;590(Pt 8):1787-801.

10. Marfella R, Siniscalchi M, Portoghese M, Di Filippo C, Ferraraccio F, Schiattarella C, et al. Morning blood pressure surge as a destabilizing factor of atherosclerotic plaque: Role of ubiquitin-proteasome activity. Hypertension 2007;49:784-91.

11. Yan Z-P, Ma J-X. Risk Factors for Diabetic Retinopathy in Northern Chinese Patients with Type 2 Diabetes Mellitus. Int $J$ Ophthalmol. 2016;9(8). doi:10.18240/ijo.2016.08.17.

12. Kuwajima I, Mitani K, Miyao M, Suzuki Y, Kuramoto K, Ozawa T. Cardiac implications of the morning surge in blood pressure in elderly hypertensive patients: relation to arising time. Am J Hypertens. 1995;8:29-33.

13. White WB. The risk of waking-up: impact of the morning surge in blood pressure. Hypertension 2010;55:835-837

14. Lambert EA, Chatzivlastou K, Schlaich M, Lambert G, Head GA. Morning surge in blood pressure is associated with reactivity of the sympathetic nervous system. Am J Hypertens. 2014;27:783-792.

15. Juhanoja EP, Puukka PJ, Johansson JK, Niiranen TJ, Jula AM. The impact of the day of the week on home blood pressure: the Finn-Home study. Blood Press Monit. 2016;21:63-68.

16. Sheng CS, Cheng YB, Wei FF, et al. Diurnal blood pressure rhythmicity in relation to environmental and genetic cues in untreated referred patients. Hypertension. 2017;69:128-135.

17. Strazzullo P, Barbato A, Galletti F, et al. Abnormalities of renal sodium handling in the metabolic syndrome. Results of the Olivetti Heart Study. J Hypertens 2006;24: 1633-1639

18. Matheus AS, Tannus LR, Cobas RA, Palma CC, Negrato CA, Gomes MB. Impact of diabetes on cardiovascular disease: an update. Int J Hypertens. 2013;2013:653789.

19. Centers for Disease Control and Prevention. National diabetes statistics report: Estimates of diabetes and its burden in the United States, 2014. Atlanta, GA: US Department of Health and Human Services; 2014.

20. Leon BM, Maddox TM. Diabetes and cardiovascular disease: Epidemiology, biological mechanisms, treatment recommendations and future research. World $\mathrm{J}$ diabetes. 2015; 6(13): 1246-1258.

21. King RJ, Grant PJ. Diabetes and cardiovascular disease: pathophysiology of lifethreatening epidemic. Herz. 2016; 41: 184-192

22. Vinik AI, Erbas T, Park TS, Nolan R, Pittenger GL. Platelet dysfunction in type 2 diabetes. Diabetes Care. 2001;24:1476-1485.

23. Vischer UM, Emeis JJ, Bilo HJ, Stehouwer CD, Thomsen C, Rasmussen O, Hermansen K, Wollheim CB, Ingerslev J. von Willebrand factor (vWf) as a plasma marker of endothelial activation in diabetes: improved reliability with parallel Jurnal Averrous Vol.5 No.1 Mei 2019 
determination of the vWf propeptide (vWf: AgII) Thromb Haemost. 1998;80:10021007.

24. Sobel BE, Woodcock-Mitchell J, Schneider DJ, Holt RE, Marutsuka K, Gold H. Increased plasminogen activator inhibitor type 1 in coronary artery atherectomy specimens from type 2 diabetic compared with nondiabetic patients: a potential factor predisposing to thrombosis and its persistence. Circulation. 1998;97:2213-2221.

25. Adler AI, Stratton IM, Neil HA, Yudkin JS, Matthews DR, Cull CA, Wright AD, Turner RC, Holman RR. Association of systolic blood pressure with macrovascular and microvascular complications of type 2 diabetes (UKPDS 36): prospective observational study. BMJ. 2000 Aug 12; 321(7258):412-9.

26. Ohishi, M. Hypertension with diabetes mellitus: physiology and pathology. Hypertens Res (2018).

27. Yaogai Lv, Yao Y, Ye J, Guo X, Dou J, Shen L, Zhang A, Xue z, Yu Y, Jin L, Association of Blood Pressure with Fasting Blood Glucose Levels in Northeast China: A Cross-Sectional Study. Sci Rep 2018; 8: 7917.

28. Ramadhan N, Hanum S. Kontrol Glikemik pada penderita Diabetes melitius tipe 2 di puskesmas jayabaru Kota Banda Aceh. SEL;2016.3(1):1-9.

29. Yan Z-P, Ma J-X. Risk Factors for Diabetic Retinopathy in Northern Chinese Patients with Type 2 Diabetes Mellitus. Int $J$ Ophthalmol. 2016;9(8). doi:10.18240/ijo.2016.08.17.

30. Marler JR, Price TR, Clark GL, et al. Morning increase in onset of ischemic stroke. Stroke. 1989;20: 473-476.

31. Muller JE, Stone PH, Turi ZG, et al. The MILIS Study Group. Circadian variation in the frequency of onset of acute myocardial infarction. $\mathrm{N}$ Engl $\mathrm{J}$ Med. 1985;313:1315-1322.

32. Osanai T, Okuguchi T, Kamada T, et al. Salt-induced exacerbation of morning surge in blood pressure in patients with essential hypertension. J Hum Hypertens. 2000;14:57-64

33. Wang YP, Li ZP, Bai Q, et al. Current status of morning blood pressure control and medication of hypertensive patients in Beijing. Chin J Cardiol. 2013;41:587-588.

34. Oh SW, Han SY, Han KH, et al. APrODiTe investigators. Morning hypertension and night non-dipping in patients with diabetes and chronic kidney disease. Hypertens Res. 2015;38:889-894.

35. Hoshide S, Yano Y, Haimoto H, et al. J-HOP Study Group. Morning and evening home blood pressure and risks of incident stroke and coronary artery disease in the Japanese general practice population: the Japan Morning Surge-Home Blood Pressure Study. Hypertension. 2016;68:54-61.

36. Kario K, Saito I, Kushiro T, et al. Home blood pressure and cardiovascular outcomes in patients during antihypertensive therapy: primary results of HONEST, a largescale prospective, real-world observational study. Hypertension. 2014;64:989-996.

37. Yoda Koichiro, et al. Association between glycemic control and morning blood pressure surge with vascular dysfunction endothelial in type 2 diabetc patients. Diabetes Care. 2014. 37; 644-650

38. Hishikawa K, L"uscher TF. Pulsatile stretch stimulatessuperoxideproductioninhuman aortic endothelial cells. Circulation 1997; 96:3610-3616

39. Eto M, Toba K, Akishita M, et al. Reduced endothelial vasomotor function and enhanced neo intimal formation after vascular injury in a rat model of blood pressure lability. Hypertens Res 2003;26:991-998. 